\title{
Sexual dysfunction in Assyrian/Syrian immigrants and Swedish-born persons with type 2 diabetes
}

\author{
Marina Taloyan ${ }^{1,2^{*}}$, Alexandre Wajngot ${ }^{3}$, Sven-Erik Johansson ${ }^{1,3}$, Jonas Tovi ${ }^{3}$ and Kristina Sundquist ${ }^{1}$
}

\begin{abstract}
Background: Few studies have investigated sexual dysfunction in immigrant patients with type 2 diabetes in Sweden. The aim of this study was to examine the association between ethnicity and sexual dysfunction and to analyze if this association remains after adjusting for explanatory variables including age, marital status, HbA1c, triglycerides, and hypertension. This cross-sectional study was conducted at four primary health care centers in the Swedish town of Södertälje. A total of 354 persons with type 2 diabetes (173 Assyrians/Syrians and 181

Swedish-born patients) participated in the survey. The main outcome measure was the self-reported presence of sexual dysfunction based on two questions, one regarding loss of ability to have sexual intercourse and the other loss of sexual desire. Response rates were $78 \%$ and $86 \%$, respectively.

Findings: The total prevalence of loss of ability to have intercourse was $29.5 \%$. In the multivariate models, the odds of loss of ability to have intercourse was significantly higher in the oldest age group $(\mathrm{OR}=5.80 ; 95 \% \mathrm{Cl}, 2.33-14.40)$, in men $(\mathrm{OR}=3.33 ; 95 \% \mathrm{Cl}, 1.33-8.30)$, and in unmarried individuals $(\mathrm{OR}=2.40 ; 95 \% \mathrm{Cl}, 1.02-5.70)$. The odds of reporting loss of sexual desire was higher in Assyrians/Syrians than in Swedish-born patients and increased from 2.00 in the age- and gender-adjusted model to 2.70 in the fully adjusted model when all confounders were taken into account.
\end{abstract}

Conclusions: Sexual dysfunction appears to be more common in Assyrians/Syrians than in Swedish-born patients. Health care workers should actively ask about sexual function in their patients with type 2 diabetes.

Keywords: Sexual dysfunction, Diabetes type 2, Immigrants, Sweden

\section{Findings}

\section{Background}

Individuals with type 2 diabetes have a higher prevalence of sexual dysfunction than those without type 2 diabetes $[1,2]$. Although type 2 diabetes is more common among some immigrant groups, few studies have investigated sexual dysfunction in immigrants with type 2 diabetes. One of these few studies was a Swedish study exploring beliefs about health and illness in men with diabetes [3]. This study showed that sexual function was one of the most important health-promoting factors for Arab men and men from the former Yugoslavia, whereas it was less important among Swedish men [3]. Most studies on the

\footnotetext{
* Correspondence: marina.taloyan@sll.se

${ }^{1}$ Center for Primary Health Care Research, Region Skåne/Lund University, CRC, hus 28, plan 11, Jan Waldenströms gata 35, SUS, 20502 Malmö, Sweden

${ }^{2}$ Stress Research Institute, Stockholm University, SE -106 91 Stockholm, Sweden

Full list of author information is available at the end of the article
}

topic have investigated men and women separately. For instance, many studies have focused on erectile dysfunction (ED) in men [4], which has been recognized as a complication of diabetes. One study in 1312 Korean men with type 2 diabetes concluded that they had a six times higher prevalence of ED than the general male population [5]. Malavige et al. showed that ED in men in Sri Lanka was strongly associated with reduced libido [6].

The effects of diabetes on sexual function have been less thoroughly studied in women than in men [4], although there is a growing number of studies of female sexual dysfunction. In Malaysian women, older age, longer marriage, having many children, and having a level of higher education were risk factors for sexual dysfunction [7]. Young Turkish women with type 2 diabetes (mean age: 38.8 years) had a higher prevalence of lack of libido than age-matched healthy women $(77 \%$ vs. $20 \%$, respectively) [8]. 
A Swedish study assessing sexual function in patients with chronic disorders found that general sexual functioning decreased with age and was most common in patients with diabetes, with loss of erection function a dominant factor [9]. This was explained by the presence of microvascular complications, psychiatric disease, and treatment with nitroglycerine. The same study found that diabetes was a secondary risk factor for decreased sexual function in patients with angina pectoris [9].

In Sweden there are approximately 70,000 to 80,000 Assyrians/Syrians [10], originating mainly from Turkey, Syria, Iraq, and Lebanon. About 20,000 Assyrians/ Syrians live in the town of Södertälje. Assyrians/Syrians are an ancient ethnic group from Mesopotamia whose Christian religion is an important part of their identity [11]. Assyrians belong to one of four churches: SyrianOrthodox, Nestorian, Chaldeian, and Syrian-Catholic. Individuals from the Syrian-orthodox group and those who do not want to be defined as Assyrians may identify themselves as Syrians [12]. Thus, both terms were used in the present study.

Few studies have investigated sexual function/dysfunction in immigrants with type 2 diabetes in general or in Assyrians/Syrians with type 2 diabetes in particular. As sexual health is an important issue and patients themselves might be embarrassed to tell their doctor about their sexual dysfunction, this study aimed to fill this gap in the literature. To the best of our knowledge, this is the second study on self-reported sexual health and the first on self-reported sexual dysfunction in a population consisting of Assyrians/Syrians and Swedes. Our first study in the same Assyrian/Syrian sample investigated dissatisfaction with one's sexual life compared to Swedish-born patients with type 2 diabetes [13]. That study showed no significant ethnic differences in the dissatisfaction with one's sexual life [13].

The first aim of the current study was to examine whether there is an association between ethnicity and self-reported sexual dysfunction in patients with type 2 diabetes. The second aim was to analyze whether this association remained after adjusting for explanatory variables including age, gender, marital status, raised triglyceride levels, and hypertension.

\section{Methods}

\section{Study setting and participants}

This study is based on the same survey that was used to investigate ethnic differences in dissatisfaction with one's sexual life and published in BMC Public Health (2010) [13]. The participants were consecutively selected from the registers of patients with type 2 diabetes at four primary health care centers in Södertälje. A total of 354 persons were included in the survey: 173 Assyrians/ Syrians and 181 Swedes. Ethnicity is discussed further in the section on explanatory variables below. Medical information and laboratory data were gathered from the patient records of all participants.

\section{Main outcome measure}

The main outcome measure was the presence of sexual dysfunction. Presence of sexual dysfunction was ascertained on the basis of the participants' answers to two questions about sexual life that were asked as part of a questionnaire on type 2 diabetes in Assyrians/Syrians and Swedish-born individuals in Södertälje. Those questions were not a part of a validated questionnaire and the purpose of including them in the health survey was to study subjective perceptions of type 2 diabetes patients about their sexual life.

The first question was "Do you have the ability to have sexual intercourse?" Responses were divided into two groups: "yes" and "no". The second question was "Do you have any sexual desire?", the answers to which were categorized as "yes" or "no". Prior to asking the two questions on sexual life, we stated to the participants that these particular questions may be perceived as being sensitive, but we asked them to answer them as well as they could.

\section{Explanatory variables}

Age was divided into three groups: 32-59, 60-69, and $\geq 70$ years. There were similar numbers of patients in the groups.

Self-reported ethnicity was defined as Assyrian/ Syrian or Swedish-born. The Swedish-born group was ethnically homogeneous. The Assyrian/Syrian ethnic group included both first- and second-generation immigrants; that is, individuals born abroad and individuals with at least one parent who was born abroad.

There is no registration of ethnicity in official Swedish statistics; rather, immigrants are identified by country of birth, parents' country of birth, and/or citizenship. For this reason, the identification of potential participants by ethnicity took place as follows: First, we created a list of the patients with diabetes type 2 at each of the four participating primary health care centers. Second, we identified Swedes and Assyrians/Syrians based on the patients' surnames and the personnel's personal knowledge of the patients. Then, each health care center's personnel contacted prospective participants by phone and invited them to fill out the questionnaire at the primary health care center. The participants were interviewed face-toface at the primary health care centers after verbal agreement by phone. One of the questions in the questionnaire was about ethnicity. Two persons who identified themselves as neither Assyrian/Syrian nor Swedishborn were excluded from the study.

Marital status was divided into two groups: 1) married or cohabiting and 2) living alone or with children 
only. We combined those living alone with those living with children because of the small number of participants among Assyrians/Syrians who were living alone.

HbA1c was divided into two groups: normal $(\leq 6.0 \%)$ and high (> 6.0\%) (Swedish mono-S method [14]).

Triglycerides were divided into normal $(<1.7 \mathrm{mmol} /$ $\mathrm{L})$ and increased $(\geq 1.7 \mathrm{mmol} / \mathrm{L})$ levels.

\section{Hypertension}

Systolic blood pressure was dichotomized as normal ( $\leq$ $130 \mathrm{mmHg}$ ) and high (> $130 \mathrm{mmHg})$. Diastolic blood pressure was divided into normal $(\leq 80 \mathrm{mmHg})$ and high ( $>80 \mathrm{mmHg}$ ). If systolic blood pressure was $>130 \mathrm{mmHg}$ and/or the diastolic blood pressure $>80 \mathrm{mmHg}$, the patient was considered to be hypertensive; otherwise, the patient was considered to be non-hypertensive.

\section{Statistical analyses}

Estimation of the prevalence of the outcome variable and determination of the differences in socio-demographic and medical characteristics between the two ethnic groups were performed using several tests. The KolmogorovSmirnov test was used to explore the parameter distribution. Correlations were assessed by using Pearson's and Spearman's methods for normally and non-normally distributed data. In addition, the unpaired two-sided Student's $t$ test was used to compare the means of normally distributed parameters. For comparison of nonnormally distributed parameters, Mann-Whitney $U$ test was performed. The statistical software used was Stata version 9 [15]. Unconditional logistic regression analysis was applied to estimate the odds ratios (ORs) and 95\% confidence intervals (CIs) for the associations between sexual dysfunction and the explanatory variables. We created two models to assess differences in lack of sexual ability: one model adjusted for age and sex and the other, fully adjusted model included age, sex, marital status, HbA1c, triglycerides, and hypertension. We lacked information on menopausal status and therefore did not control for this variable. Reference groups were the following: age 3259 years, male sex, being married/cohabiting, HbA1c $<6 \%$, raised triglycerides, and having hypertension. The fit of the models was judged by the Hosmer-Lemeshow goodness-of-fit test [16].

\section{Ethical considerations}

The study was approved by the regional ethical committee at Karolinska Institutet (reference number 2006/4:8, 2006-09-27). The respondents provided verbal informed consent for participation in the study and for the gathering of data from patient records. They gave the same verbal consent to participate on two occasions: once by phone and once before starting the face-to-face interviews at the primary health care centers.

\section{Results}

In total, 354 participants filled out the questionnaire. The Swedish population was somewhat older, with a mean age of 64 years (range: $32-86$ years), as shown in Table 1. The Assyrian/Syrian population was younger with a mean age of 61 years (range: $32-83$ years). There seemed to be ethnic differences in the duration of type 2 diabetes, which was self-reported and based on the age of the participants when the diagnosis was made, but these differences were not statistically significant. The same pattern was observed for diabetes control with a mean HbA1c of 6.1\% (SD 1.2) in Swedish-born patients and 6.3\% (SD 1.6) in Assyrians/Syrians.

Table 2 presents the total prevalences of the outcome variables; $78 \%$ of participants $(n=273)$ answered the first question about their ability to have sexual intercourse. Among Assyrians/Syrians the response rate was 65\% $(\mathrm{n}=112)$, and among Swedish-born patients the response rate was $89 \%(n=161)$. The total prevalence of lack of ability to have intercourse was $29.5 \%$. No significant differences were noted between the ethnic groups:

\begin{tabular}{|c|c|c|c|}
\hline Sociodemographic variables & $\begin{array}{l}\text { Assyrians/ } \\
\text { Syrians } \\
\mathrm{n}=173\end{array}$ & $\begin{array}{l}\text { Swedes } \\
n=181\end{array}$ & $\begin{array}{l}\text { Test of } \\
\text { differenc } \\
\mathrm{P} \text { value }\end{array}$ \\
\hline Total & 48.9 & 51.1 & \\
\hline \multicolumn{4}{|l|}{ Gender } \\
\hline Female & $48.5(84)$ & $44.2(80)$ & $0.411^{\mathrm{a}}$ \\
\hline Male & $51.5(89)$ & $55.8(101)$ & \\
\hline \multicolumn{4}{|l|}{ Age (years) } \\
\hline $32-57$ & $39.3(68)$ & $27.1(49)$ & $0.003^{b}$ \\
\hline $58-70$ & $37.0(64)$ & $41.4(75)$ & \\
\hline$>70$ & $23.7(41)$ & $31.5(57)$ & \\
\hline HbA1c (MD) & 6.0 & 5.8 & $0.28^{c}$ \\
\hline$(>6 \%)$ & 49.7 & 40.6 & $0.10^{c}$ \\
\hline Smoking habits (yes) & $16.9(29)$ & $18.3(29)$ & $0.63^{\mathrm{a}}$ \\
\hline \multicolumn{4}{|l|}{ Anthropometric data } \\
\hline Body mass index (MD) & 31.3 & 29.1 & $0.0049^{b}$ \\
\hline \multicolumn{4}{|l|}{ BMI $\left(\mathrm{kg} / \mathrm{m}^{2}\right)$} \\
\hline Normal $(<25)$ & $11.8(20)$ & $15.0(27)$ & $0.017^{c}$ \\
\hline Overweight (25.0 - 29.9) & $30.6(52)$ & $42.5(76)$ & \\
\hline Obese $(\geq 30)$ & $57.6(98)$ & $42.5(76)$ & \\
\hline Duration (age of onset) (MD) & 54 & 56 & $0.096^{c}$ \\
\hline $30-45$ & $29.0(42)$ & $21.0(30)$ & $0.090^{b}$ \\
\hline $46-60$ & $60.0(87)$ & $61.0(89)$ & \\
\hline$>60$ & $11.0(16)$ & $18.0(27)$ & \\
\hline
\end{tabular}

a Pr-test.

${ }^{b}$ Chi2-test.

c Mann-Whitney tes. 
the prevalence was $28.3 \%$ among the Assyrians/Syrians and $30.4 \%$ among the Swedish-born respondents. On the other hand, there were differences according to sex: $76.5 \%$ of men and $23.5 \%$ of women reported loss of ability to have sexual intercourse.

The total response rate for the question about sexual desire was $86 \%(n=301)$. Among Assyrians/Syrians the response rate was $76 \%(\mathrm{n}=132)$, and among Swedishborn patients the response rate was $93 \%(n=169)$. Significant differences were noted in loss of sexual desire only between Assyrian/Syrian and Swedish women.

In Table 3, ORs for loss of ability to have sexual intercourse are shown in a model adjusted for age and sex and in a final model. After adjusting for age and sex, the odds of loss of ability to have intercourse were 5.00 times higher in those $\geq 70$ years of age $(95 \%$ CI, 2.10 11.40) than in those $32-59$ years old. Furthermore, men had higher odds of reporting loss of ability to have sexual intercourse than women $(\mathrm{OR}=3.01 ; 95 \% \mathrm{CI}, 1.30$ 7.23). In the fully adjusted model, the odds of reporting loss of ability to have sexual intercourse was higher in those aged $\geq 70$ years $(\mathrm{OR}=5.80 ; 95 \% \mathrm{CI}, 2.33-14.40)$, in men $(\mathrm{OR}=3.33 ; 95 \% \mathrm{CI}, 1.33-8.30)$. Moreover, the results for the full model showed that those living alone or with children had higher odds of reporting loss of ability to have sexual intercourse $(\mathrm{OR}=2.40 ; 95 \% \mathrm{CI}$, 1.02-5.70) than those who were married or cohabiting.

As shown in Table 4, the odds of reporting loss of sexual desire were two times higher in the Assyrian/Syrian group than in the Swedish-born participants in the ageand sex-adjusted model $(\mathrm{OR}=2.00 ; 95 \% \mathrm{CI}, 1.02-4.00)$. Both the older age groups (60-69 years and $\geq 70$ years) had higher odds of reporting loss of sexual desire (OR = 2.20 and $\mathrm{OR}=4.50$, respectively) than the youngest age group. Women had more than seven times higher odds of loss of sexual desire than men $(\mathrm{OR}=7.10,95 \% \mathrm{CI}$, 3.70-13.60).

In the fully adjusted model, the ORs for reporting loss of sexual desire remained higher for the oldest age group $(\mathrm{OR}=4.60 ; 95 \% \mathrm{CI}, 2.00-11.00)$ and for women $(\mathrm{OR}=$ 6.54; 95\% CI, 3.40-13.00), regardless of ethnicity. Furthermore, those who lived without a partner had higher odds of loss of sexual desire than married individuals $(\mathrm{OR}=2.42$; 95\% CI, 1.20-5.01). The odds of loss of sexual desire were significantly higher in Assyrians/Syrians than in Swedish-born subjects (OR $=2.70,95 \%$ CI, 1.305.50). The models were considered acceptable if $\mathrm{p}$ was $<$ 0.05 in a likelihood ratio test. All models met this demand [16].

\section{Discussion}

In this study, the self-reported loss of ability to have intercourse was not associated with ethnicity. On the other hand, self-reported loss of sexual desire was independently associated with ethnicity (Assyrian/Syrian vs. Swedish-born) in the fully adjusted model. In addition, loss of ability to have intercourse was independently related to older age, male sex, and living without a partner.

Advanced age is a risk factor for poor general health $[17,18]$ and diabetes [19]. The sexual lives of individuals are influenced by several health and socio-demographic factors. According to studies investigating this subject, the following are risk factors for the absence of a normal sexual life in diabetic individuals: sexual dissatisfaction, lack of orgasm/erection, low sexual arousal, lack of lubrication, and sexual pain. A study of 230 married Malaysian women showed that factors such as older age, being married more than 14 years, and having less sexual intercourse were associated with a lack of lubrication [7]. A large study of 7,243 healthy middle-aged women aged 40-59 found that the prevalence of sexual dysfunction was high but differed between different populations. The most important associated risk factor was a decrease in vaginal lubrication. Additionally, and in contrast to the study of Malaysian women, higher educational level protected against sexual dysfunction [20]. The female participants of Assyrian/Syrian origin in the present study have a low educational level and $20 \%$ of the Assyrian/Syrian participants are illiterate [ $25 \%$ of women and $14.6 \%$ of men], which may highlight the need for prospective studies exploring the association between educational level and sexual life.

Sexual dysfunction in women might be related to the menopausal status and the negative impact of menopause on sexuality [21,22]. A study in American women aged 30 to 70 years who had been in stable relationships for more than 3 months concluded that the prevalence of low sexual desire is higher in menopausal women than in premenopausal women [23]. Another study assessing the prevalence of sexual dysfunction in premenopausal women showed that, compared to the control group, those with the metabolic syndrome had reduced sexual function [24]. The associations between sexuality, hyperglycemia, elevated body weight, and the metabolic syndrome are also strong in menopausal women [25].

Relationships between hyperglycemia and higher BMI and lipid abnormalities were observed in several studies [26-28]. Despite the fact that $48 \%$ of the participants in the current study had BMI values higher than $30 \mathrm{~kg} / \mathrm{m}^{2}$, the BMI variable was not a statistically significant confounder. Our results are based on self-reporting, and physical health and culture may have influenced the responses to sensitive questions on sexuality. It is important to note that, due to cultural and religious values, individuals with an Assyrian/Syrian ethnic background were presumed to only have a sexual life within the context of marriage [12]. 
Assyrians/Syrians are an ancient ethnic group from Mesopotamia. The Christian religion is one of the important parts of their identity [29]. The majority of the participants in the present study accepted their diabetes as being sent by God and the separation from or loss of a life partner was not followed by another partner. "We do not do that", said the separated woman when we asked whether she had a sexual partner or not. Perhaps this was one of the reasons for the proportion of Assyrians/Syrians who responded to this question being smaller compared to the proportion of Swedish-born participants. On the other hand, patients' perceptions of sex and sexual practices may be individual. This might be investigated more deeply using valid and standardized scales on sexual life and sexual function.

\section{Strengths and limitations}

This study has several strengths. Registration by ethnicity does not occur in the official Swedish statistics, where immigrants are identified according to country of birth, parents' country of birth, and/or citizenship. A unique feature of this study is the use of data on selfreported ethnicity and its main strength is that it is the first study of sexual life in Assyrians/Syrians with type 2 diabetes. Another strength of this study is the inclusion of patients from several health care centers; the sample can therefore be considered highly representative of Assyrians/Syrians in Södertälje.

One limitation of the study is that the instrument used to explore sexual dysfunction has not been validated. Another limitation is that it assessed Assyrian/Syrian patients with type 2 diabetes living in one town and the results cannot therefore be generalized to the entire Assyrian/Syrian population with diabetes in Sweden. A third limitation is that the cross-sectional nature of the study and the relatively small sample size precluded the possibility of drawing extensive causal conclusions.

\section{Conclusions}

Loss of sexual desire was independently associated with ethnicity (Assyrian/Syrian vs. Swedish-born) in the fully adjusted model. Sexual function is an important part of general health status and quality of life and should be included in the clinical evaluation of patients with type 2 diabetes. The results of this study suggest that physicians and other health care workers should feel encouraged to ask about sexual function in their patients, regardless of the patients' ethnic background, age, or sex.

\section{Abbreviations}

Cl, Confidence interval; GP, General practitioner; OR, Odds ratio.

\section{Competing interests}

The authors declare that they have no competing interests.

\section{Authors' contributions}

MT conceived the idea for the survey. MT, AW, JT, SEJ and KS designed the study. MT and SEJ performed the statistical analysis. MT drafted the manuscript. KS, AW, JT and SEJ revised the manuscript. All authors read and approved the final manuscript.

\section{Acknowledgements}

This work was supported by grants from the Research Unit in Södertälje, the Swedish Research Council (2008-3110), the Swedish Council for Working Life and Social Research (2007-1754 and 2007-1962) and the Swedish Research Council Formas (2007-1352).

The authors had no conflicts of interest. The funding bodies played no role in the study design or the collection, analysis, and interpretation of data, the writing of the manuscript, or the decision to submit the manuscript for publication. We thank all the GPs and personnel at the primary health care centers who contributed to the study by gathering data. Furthermore, we thank Scientific Editor Kimberly Kane and Stephen Gilliver for linguistic revision of the manuscript and useful comments on the text.

\section{Author details}

${ }^{1}$ Center for Primary Health Care Research, Region Skåne/Lund University, CRC, hus 28, plan 11, Jan Waldenströms gata 35, SUS, 20502 Malmö, Sweden. ${ }^{2}$ Stress Research Institute, Stockholm University, SE -106 91 Stockholm, Sweden. ${ }^{3}$ Karolinska Institutet, Center for Family and Community Medicine, Alfred Nobels allé 12, SE -141 83 Huddinge, Sweden.

Received: 15 November 2011 Accepted: 20 September 2012 Published: 24 September 2012

\section{References}

1. Olarinoye J, Olarinoye A: Determinants of sexual function among women with type 2 diabetes in a Nigerian population. J Sex Med 2008, 5(4):878886.

2. Mezones-Holguin E, Blumel JE, Huezo M, Vargas R, Castro J, Cordova W, Valenzuela G, Castelo-Branco C: Impact of diabetes mellitus on the sexuality of Peruvian postmenopausal. Gynecol Endocrinol 2008, 24(8):470-474.

3. Hjelm K, Bard K, Nyberg P, Apelqvist J: Swedish and Middle-Eastern-born women's beliefs about gestational diabetes. Midwifery 2005, 21(1):44-60.

4. Ghalayini IF, Al-Ghazo MA, Al-Azab R, Bani-Hani I, Matani YS, Barham AE, Harfeil MN, Haddad Y: Erectile dysfunction in a Mediterranean country: results of an epidemiological survey of a representative sample of men. Int J Impot Res 2010, 22:196-203.

5. Cho NH, Ahn CW, Park JY, Ahn TY, Lee HW, Park TS, Kim IJ, Pomerantz K, Park C, Kimm KC, et al: Prevalence of erectile dysfunction in Korean men with Type 2 diabetes mellitus. Diabet Med 2006, 23(2):198-203.

6. Malavige LS, Jayaratne SD, Kathriarachchi ST, Sivayogan S, Fernando DJ, Levy JC: Erectile dysfunction among men with diabetes is strongly associated with premature ejaculation and reduced libido. J Sex Med 2008, 5(9):2125-2134.

7. Sidi H, Puteh SE, Abdullah N, Midin M: The prevalence of sexual dysfunction and potential risk factors that may impair sexual function in Malaysian women. J Sex Med 2007, 4(2):311-321.

8. Erol B, Tefekli A, Ozbey I, Salman F, Dincag N, Kadioglu A, Tellaloglu S: Sexual dysfunction in type II diabetic females: a comparative study. J Sex Marital Ther 2002, 28(Suppl 1):55-62.

9. Wandell PE, Brorsson B: Assessing sexual functioning in patients with chronic disorders by using a generic health-related quality of life questionnaire. Qual Life Res 2000, 9(10):1081-1092.

10. Nordgren K: Who Does History Belong To? History as Consciousness, Culture and Action in Multicultural Sweden. Karlstad, Sweden: Karlstad University; 2006.

11. Deniz F: The maintaining and the transformation of the ethnic identity in relation to the process of the modernization: The Assyrian example. Uppsala: Uppsala University, Faculty of Social Sciences, Department of Sociology; 1999.

12. Deniz F: The maintaining and the transformation of the ethnic identity in relation to the process of the modernization: The Assyrian example, PhD thesis. Uppsala, Sweden: Uppsala University; 1999. 
13. Taloyan M, Wajngot A, Johansson SE, Tovi J, Sundquist J: Ethnic differences in dissatisfaction with sexual life in patients with type 2 diabetes in a Swedish town. BMC Public Health 2010, 10:536.

14. Eckerbom S, Bergqvist Y, Jeppsson JO: Improved method for analysis of glycated haemoglobin by ion exchange chromatography. Ann Clin Biochem 1994, 31(Pt 4):355-360.

15. StataCorp: Stata Statistical Software: Release 9.2. College station. TX: Stata Corporation; 2007.

16. Hosmer D, Lemeshow S: Applied Logistic Regression. 2nd edition. New York: John Wiley\&Sous Inc.; 2002.

17. McEwen LN, Kim C, Haan MN, Ghosh D, Lantz PM, Thompson TJ, Herman WH: Are health-related quality-of-life and self-rated health associated with mortality? Insights from Translating Research Into Action for Diabetes (TRIAD). Prim Care Diabetes 2009, 3(1):37-42.

18. Unden AL, Elofsson S, Andreasson A, Hillered E, Eriksson I, Brismar K: Gender differences in self-rated health, quality of life, quality of care, and metabolic control in patients with diabetes. Gend Med 2008, 5(2):162-180.

19. Fatemi SS, Taghavi SM: Evaluation of sexual function in women with type 2 diabetes mellitus. Diab Vasc Dis Res 2009, 6(1):38-39.

20. Blumel JE, Chedraui P, Baron G, Belzares E, Bencosme A, Calle A, Espinoza MT, Flores $D$, Izaguirre $H$, Leon-Leon $P$, et al: Sexual dysfunction in middleaged women: a multicenter Latin American study using the Female Sexual Function Index. Menopause 2009, 16(6):1139-1148.

21. Buvat J, Lemaire A: Sexuality of the diabetic woman. Diabetes Metab 2001, 27(4 Pt 2):S67-S75.

22. Basson R: Rethinking low sexual desire in women. Bjog 2002, 109(4):357363.

23. West SL DAA, Agans RP, Kalsbeek WD, Borisov NN, Thorp JM: Prevalence of low sexual desire and hypoactive sexual desire disorder in a nationally representative sample of US women. Arch Intern Med 2008 Jul 14, 168 (13):1441-1449.

24. Esposito K, Ciotola M, Marfella R, Di Tommaso D, Cobellis L, Giugliano D: The metabolic syndrome: a cause of sexual dysfunction in women. Int $J$ Impot Res 2005, 17(3):224-226.

25. Chedraui P, Perez-Lopez FR, Mendoza M, Morales B, Martinez MA, Salinas AM, Hidalgo L: Severe menopausal symptoms in middle-aged women are associated to female and male factors. Arch Gynecol Obstet 2010, 281 (5):879-885.

26. Ghergerehchi R: Dyslipidemia in Iranian overweight and obese children Ther Clin Risk Manag 2009, 5:739-743.

27. Paschoal MATP, Scodeler NF: Heart rate variability, blood lipids and physical capacity of obese and non-obese children. Ara Bras Cardiol 2009, Sep, 93(3):239-246.

28. Taylor HA CS Jr, Levy D, Walker ER, Vasan RS, Liu J, Akylbekova EL, Garrison RJ, Fox C: Relationships of BMI to Cardiovascular Risk Factors Differ by Ethnicity. Obesity (Silver Spring) 2009 Nov 19, Epub ahead of print

29. Freyne-Lindhagen M: Identity and cultural encounterr: The Syrian women example. Lund: Studentlitteratur; 1997.

doi:10.1186/1756-0500-5-522

Cite this article as: Taloyan et al: Sexual dysfunction in Assyrian/Syrian immigrants and Swedish-born persons with type 2 diabetes. BMC

Research Notes 2012 5:522.

\section{Submit your next manuscript to BioMed Central and take full advantage of:}

- Convenient online submission

- Thorough peer review

- No space constraints or color figure charges

- Immediate publication on acceptance

- Inclusion in PubMed, CAS, Scopus and Google Scholar

- Research which is freely available for redistribution 